\title{
"A GENTE TRABALHAVA, ROÇAVA, FAZIA O DIACHO. DEPOIS FOI QUE VEIO ESSE NEGÓCIO DE IBAMA E TRANCOU TUDO: CONSERVAÇÃO E CONFLITO SOCIOAMBIENTAL NO ALTO DO MORRO DA FONTE GRANDE (VITÓRIA - ES)"'
}

\author{
"WE WORKED, BRUSHED, MADE THE DEVIL. THEN THIS IBAMA THING CAME AND \\ LOCKED EVERYTHING: CONSERVATION AND SOCIO-ENVIRONMENTAL CONFLICT ON \\ TOP OF MORRO DA FONTE GRANDE (VITÓRIA - ES)”
}

\section{Márcio Antônio Farias de Freitas 2}

RESUMO: Este artigo é resultado de minha pesquisa de mestrado em Ciências Sociais realizado na Universidade Federal do Espírito Santo -, que vem refletir sobre o conflito socioambiental existente no Campinho, situado no alto do morro da Fonte Grande (Vitória-ES), cenário de uma disputa por um espaço urbano "verde" imprensado entre duas secções de uma área de proteção integral. A área ocupada há gerações pelo coletivo "virou" parque, e não se pode mais caçar, coletar ou plantar. Os recursos naturais foram delimitados e nem mesmo sobre o espaço de suas moradias eles têm mais controle e autonomia, visto que há uma proibição relativa à construção ou reforma dos imóveis por estarem, segundo a Prefeitura Municipal de Vitória, localizados em Área de Interesse Ambiental, Zona de Proteção Ambiental e Área de Proteção Ambiental do Maciço Central. Através da etnografia, procurei seguir atores humanos e não humanos para entender as representações dos ambientalistas, gestores e técnicos ambientais bem como do coletivo. Profundamente desiguais em termos de poder político dos agentes humanos envolvidos, as perspectivas defendidas reiteram o confronto entre a preservação da oposição entre natureza e sociedade, consolidando políticas de reclusão (natural) e exclusão (social), e a permanência no local dos guardiões atuantes de outro regime de relações entre humanos e não humanos.

Palavras chave: Etnografia - conservacionismo - conflito socioambiental - morro da Fonte Grande

ABSTRACT: This article is the result of my master's research in Social Sciences - conducted at the Universidade Federal do Espírito Santo -, which comes to reflect on the socio-environmental conflict existing in Campinho, located at the top of the Morro da Fonte Grande (Vitória-ES),

\footnotetext{
I Uma versão preliminar deste artigo foi publicada nos ANAIS do $7^{\circ}$ Encontro da Associação Nacional de PósGraduação e Pesquisa em Ambiente e Sociedade, 2015, Brasília.

${ }^{2}$ Doutor em Antropologia (Universidade Nova de Lisboa); mestre em Ciências Sociais; pós-graduado (Lato Sensu) em História Social e Gestão Ambiental; e graduado (bacharelado e licenciatura) em Ciências Sociais (Universidade Federal do Espírito Santo). Membro do Centro em Rede de Investigação em Antropologia (CRIA/Portugal). Email: m.ffreitas@hotmail.com.
} 
scenario of a dispute for a "green" urban space sandwiched between two sections of an integral protection area. The area occupied for generations by the collective "turned" into a park, and it is no longer possible to hunt, collect or plant. Natural resources have been delimited and not even over the space of their homes do they have more control and autonomy, since there is a prohibition regarding the construction or renovation of properties because, according to the Prefeitura de Vitória, they are located in an Area of Environmental Interest, Environmental Protection Zone and Environmental Protection Area of the Massif Central. Through ethnography, I tried to follow human and non-human actors to understand the representations of environmentalists, managers and environmental technicians as well as the collective. Profoundly unequal in terms of the political power of the human agents involved, the defended perspectives reiterate the confrontation between the preservation of the opposition between nature and society, consolidating policies of seclusion (natural) and exclusion (social), and the permanence in place of the active guardians of another regime of relations between humans and non-humans.

Keywords: Ethnography - conservationism - socio-environmental conflict - Morro da Fonte Grande

\section{INTRODUÇÃO}

O município de Vitória, capital do estado do Espírito Santo, tornou-se palco de discursos sobre "sustentabilidade" e "ecologização", sobretudo a partir da década de 1990, com a criação do Projeto Vitória do Futuro, do Programa Terra Mais Igual (PTMI), da Área de Proteção Ambiental (APA) do Maciço Central e seu Zoneamento Ecológico-Econômico (ZEE), do Plano Diretor Urbano(PDU), e também com a administração do Parque Estadual da Fonte Grande (PEFG), transferida ao poder municipal pelo estado.

Alinhados com uma perspectiva de oposição natureza x sociedade (LATOUR, 1994; DESCOLA, 2000; VIVEIROS, 2002; INGOLD, 1995; BATESON, 2008), o poder público municipal vêm adotando um conjunto de políticas desenvolvimentistas e discursos sobre "sustentabilidade" que desconsideram as matas dos morros e seus arredores como ambientes de socialização e pertencimento de diversos coletivos da cidade. Através de processos autoritários de ordenamento e remoção territorial, é negada não só a existência de relações desses coletivos com o território, mas com os demais sujeitos que compõe a cosmografia ${ }^{3}$ do lugar, o que tem gerado diversos conflitos socioambientais (ACSELRAD, 2004).

Dentre os lugares de ocorrência desses conflitos envolvendo coletivos e o Estado, no alto

\footnotetext{
3 Conforme Paul Little (2002), seria o saber ambiental, ideologias e identidades - coletivamente criadas e historicamente situadas - que um grupo social utiliza para estabelecer e manter seu território. A cosmografia de um grupo inclui seu regime de propriedade, os vínculos afetivos que mantém com seu território específico, a história da sua ocupação guardada na memória coletiva, o uso social quedá ao território e as formas de defesa dele (Ibid.).
} 
do morro da Fonte Grande, num território conhecido como Campinho4, imprensado, desde 1986,entre as duas secções do Parque Estadual da Fonte Grande, a Prefeitura Municipal de Vitória pretende unir e conectar às demais áreas "protegidas" incluídas na Área de Proteção Ambiental do Maciço Central, retirando as famílias que lá habitam há gerações. O "discurso verde” da PMV, visando a criação de uma "cidade paisagem" e "ecologicamente correta", ao ser mobilizado, desconsidera as formas de ocupação dos moradores presentes nas Áreas de Interesse Ambiental e Zonas de Proteção Ambiental, rotulando-as enquanto “insustentáveis" do ponto de vista ambiental.

\section{Entre fontes e campinhos}

O morro da Fonte Grande, inserido numa cadeia de montanhas com vegetação remanescente da Mata Atlântica, possui essa denominação devido às inúmeras fontes existentes em sua área, responsáveis pelo fornecimento de água para grande parte de Vitória até a inauguração do serviço de abastecimento de água encanada, que só ocorreu no governo Jerônimo Monteiro, em 1909 (DERENZI, 1965; ROCHA, 2008). Atualmente, o morro da Fonte Grande, localizado na região central da capital do Espírito Santo, e fazendo limites com o PEFG,

o morro da Piedade e o Centro de Vitória, conforme dados do censo de 2010 do IBGE, possui uma população de I.23I habitantes (PMV, 2013).

Essa região apresenta registros de ocupação desde os primeiros processos de povoamento e colonização da capitania de Vitória no século XVI, já que suas fontes atraíram para suas proximidades os colonizadores na escolha dos lugares propícios para as edificações da nova sededa Capitania, conciliando a necessidade de se proteger e defender dos ataques tanto dos rivais europeus quanto dos povos indígenas originários daquelas terras, com o aproveitamento dos recursos hídricos (DERENZI, 1965), ideia corroborada por Gabriel5, antigo morador da região: “a Fonte Grande é antiga, aquilo ali tem mais de duzentos, trezentos, quatrocentos anos. A Fonte Grande não é de hoje, não é de ontem não" (Gabriel, 77 anos).

Ainda hoje existem manifestações culturais relacionadas às fontes do morro, como a festa de São Benedito (ROCHA, 2008; CICCARONE, 2010), com cânticos, congo e queima de fogos,

\footnotetext{
${ }^{4} \mathrm{O}$ morro da Fonte Grande possui vários territórios demarcados pelo coletivo com denominações bem específicas, tais como o Campinho, o Buraco Quente, a Boca da Mata, o Quebra Dedo e o Chapéu de Lado.

${ }^{5}$ Foram criados nomes fictícios para preservar a identidade dos moradores.
} 
seguidas de celebrações de missa e reza do terço na Igreja do Rosário. Destacam-se os fogos da alvorada para cumprir uma promessa das lavadeiras da Fonte Grande à São Benedito, que apesar de uma forte seca, cuidou para que essa fonte não secasse, alterando, a partir desse momento, seu nome para "São Benedito" (ROCHA, 2008; ELTON, 1986; DERENZI, 1965). Além da festa de São Benedito, há ainda outras manifestações culturais no morro, como o samba, o congo, a marujada, o cordão de ouro, as batucadas, as burrinhas e cantigas de roda (SEAG-IDAF et al., 1996), destacando-se, nesse cenário multifacetado do patrimônio imaterial do lugar, o Grêmio RecreativoEscola de Samba Unidos da Piedade, a escola mais tradicional do carnaval de Vitória, fundada em 1955 e campeã em treze oportunidades, que em 1987 homenageou as matas e fontes da Fonte Grande, que conforme Ricardo, nascido e criado no morro, "o morador da Fonte Grande não consegue se ver sem as fontes e a mata. As fontes e a mata é ele. É uma só pessoa”.

E no alto do morro da Fonte Grande, no Campinho - local estratégico onde se encontram várias trilhas que se ramificam em diversas direções dā cidade - vivem cerca de trinta e oito famílias que ocupam há gerações a localidade, com plantações, criações de galinhas, suínos e bovinos, nessa área situada no centro urbano da capital do estado do Espírito Santo, distribuindose nesse espaço em casas de madeira, alvenaria e estuque, onde, num quadro geral de baixa renda, baixa escolaridade, aumento da violência por disputa do tráfico de drogas com o morro vizinho da Piedade, falta de água encanada, esgoto e energia elétrica - por ser Área de Interesse Ambiental, Zona de Proteção Ambiental, e Área de Proteção Ambiental do Maciço Central - possuem com esse espaço de sociabilidade uma relação em que as fontes, a mata, as pedras, os animais e as trilhas transcendem os limites e proibições impostos pela PMV (FREITAS et al., 2012).

Os moradores do Campinho, através de suas narrativas, reforçam seu pertencimento ao lugar e são enriquecidas pela referência constante a acontecimentos que estabelecem uma relação dialógica entre presente, passado e futuro (SOUZA et al., 2010). Fazem referência aos "bons tempos" do Campinho, quando tinham diversas plantações no alto do morro, como no caso de dona Mônica, 55 anos, que hoje está morando numa casa na Fonte Grande, na divisa com a Piedade: “(...) nós plantamos muita coisa: bananeira, mangueira, acerola, meu marido plantou muita fruta (...). Eu tinha muita galinha (...). Criei pato também (...). Quando eu era pequena era um tempo bom, muito bom". Já dona Janete, 52 anos, baiana quechegou ao Campinho "há mais de vinte anos", conhecida no morro como "cabocla", complementava o sustento da família com 
aquilo que cultivava no quintal de sua casa:

esse quintal era todo plantado, até horta eu já tive aqui. Aqui eu tinha horta de alface, coentro, salsa, tempero, eu não comprava. Já vendi muita cana aqui, pra sobreviver, dava cada cana imensa (...). No dia que eu saí daqui, no outro dia, vieram aqui e acabaram com tudo. Eu criava muita galinha, eu gosto de criar galinha (...). Esse quintal meu era muito bom, hein? Tinha capim cidreira que eu trouxe da Bahia ali, aqui tinha muito inhame, de supermercado e de brejo, taioba, já colhi muita taioba aqui, meus meninos desciam pra vender, pimenta cheirosa, poejo, levante. Levante é um remédio que você toma quando você está com uma dor (Janete, 52 anos).

Entretanto, dona Janete não pode dar continuidade a essa atividade desde que se mudou para o morro do Quadro em novembro de 2009, com o Aluguel Provisório ${ }^{6}$ da PMV, morando atualmente numa casa sem quintal no bairro Grande Vitória: "lá não tem quintal, se você vê atrás como que tá de lama, porque a enxurrada desce, aí vai jogando aquela terra, não tem? Aí lá não tem quintal, não".

No plano de manejo do Parque Estadual da Fonte Grande, elaborado em 1996, também é possível encontrar referências à relação entre o coletivo e o território, como no item "Uso atual dos recursos naturais da região", onde há uma descrição de vários usos que ocorrem nesse território:

agricultura de subsistência: (...) ocorre em toda a região, com relativa frequência e de forma aleatória (...) os habitantes do entorno da UC, utilizam diversos tipos de ervas medicinais encontradas na área, tais como cana-de-macaco (Alpinia spiralis), caruru (Amaranthus flavus), pau-ferro (Arauma brasiliensis), carqueja (Baccharis crispa), erva-Santa-Maria (Chenapodium ambrodioides), pau-d'álho (Gallesia quararema), quebra-pedra (Phylantus miruri), e outras para cultos afrobrasileiros (SEAG-IDAF et al., 1996, p. 22).

Já no item “Caracterização do usuário da UC” se afirma que “(...) pessoas também utilizam espécies vegetais que ocorrem na área como medicamentos para cura de doenças" (Ibid., p. 30), citações essas que reforçam a existência de usos tradicionais do ambiente e indicam o conhecimento dessas práticas.

A estreita relação com o território ficou muito explícita na construção da Cartografia Social da Comunidade do Campinho da Fonte Grande, através do Projeto de Pesquisa Identidades, Territórios

\footnotetext{
${ }^{6} \mathrm{O}$ Aluguel Provisório é um projeto da Prefeitura Municipal de Vitória que busca viabilizar a concessão temporária de subsídio, integral ou parcial, para locação de imóvel residencial por famílias inseridas nas áreas de intervenção do Projeto Terra, com renda familiar mensal de até três salários mínimos ou per capita de até meio salário mínimo, que, à conveniência do Poder Público, tenham optado pela inclusão no Projeto Reassentamento (Id., 2007, Art. Io).
} 
e Cidadania ${ }^{7}$, no período de 2011 a 2012, onde se pode verificar que a relação do coletivo com as matas, trilhas e nascentes transcende aos limites impostos pelo Plano Diretor Urbano, planos de manejo, Programa Terra Mais Igual, etc. Exemplo disso é o conhecimento espacial do território, com as diversas trilhas que os liga ao Centro da cidade, a bairros como Vila Rubim, Santo Antônio, Fradinhos, Maruípe, São Pedro, dentre outros. Além disso, o coletivo nomeia os diversos atores não-humanos (LATOUR, 200I) existentes no morro associando-os sempre a um acontecimento, uma história, com seus diversos atores, como a fonte do Cajuza, da Bica ${ }^{8}$, Inocentes, Morcegos, Helena, São Benedito, Pedra do Amor, dentre outros.

\section{O "meio ambiente" chegou à Fonte Grande}

O plano de manejo da APA do Maciço Central, elaborado em 1992, faz uma breve descrição do Campinho da Fonte Grande, se referindo a ele como a zona rural do município:

(...) no centro desta malha urbana, surge acima da cota altimétrica $50 \mathrm{~m}$, a zona rural do município de Vitória, com parte de sua periferia ocupada (...). Boa parte daárea rural é destinada à conservação dos recursos naturais (...). Existem ainda pastagens com diversas fisionomias, áreas agrícolas de diversas culturas, principalmente banana, mandioca, feijão, milho e café (...). Na área existem edificações esparsas nas sedes das propriedades e de forma mais significativa no topo do morro da Fonte Grande (...) (PMV, 1992, pp. 46-47).

E conforme o relato de Gabriel, o Campinho, era, ao lado de outros, uma região rural de Vitória,com agricultura e pecuária bovina:

quando eu vim aqui pra cima, em 1950, tudo era pasto ainda, porque o pessoal tinha vaca. O pessoal de Vitória vivia de agricultura, todos eles tinham horta, pra ter horta tinha que ter adubo, esterco, então, o pessoal daqui tinha vaca, o pessoaldali tinha vaca, a família Monjardim tinha vaca, nós tínhamos vaca, todo mundo tinha vaca e era tudo aberto, não tinha esta capoeira que está aí, não existia, eramtudo as pedras e o capim, e fazia horta, a maioria das pessoas. Ali eles (os antigos moradores) carregavam verdura na cabeça até no Mercado da

\footnotetext{
7 O Projeto de Pesquisa foi financiado pelo Fundo de Apoio à Ciência e Tecnologia da Prefeitura Municipal de Vitória (FACITEC) e desenvolvido no período de zoı a 2012. Tendo como objetivo a elaboração de uma cartografia social do Campinho da Fonte Grande (Vitória-ES), visando contribuir no fortalecimento de sua organização política e pelo reconhecimento dos direitos coletivos, na promoção da cidadania e da gestão participativa do território urbano, os fascículos da Cartografia Social da Comunidade do Campinho da Fonte Grande foram entregues ao coletivo em agosto de 2012.

${ }^{8}$ Também conhecida como Poço das Mangueiras.
} 
Capixaba9 ${ }^{9}$ não tinha transporte não, chegava de madrugada, botava na cabeça, três quatro e iam embora pro mercado. Na cabeça, não tinha transporte, só tinha o bonde, o bonde vinha até Jucutuquara e ia até a Praia do Canto ${ }^{\text {io }}$.

Essa Vitória rural passou a se modificar a partir da década de 6o, fruto de um processo de industrialização com consequente explosão demográfica nos cinco municípios que compreendem a Grande Vitória, com migrantes vindos do interior do estado, além de Minas Gerais e Bahia (BANCK, 1998). E revisitando o discurso oficial, articulando outras versões das histórias de ocupação do morro da Fonte Grande, através das narrativas dos moradores (SOUZA et al., 2010), essas demonstram que o adensamento do Campinho ocorreu justamente nessa década de 6o, como consequência de um modelo hegemônico de desenvolvimento que ocasionou um intenso êxodo rural, responsável pela favelização, ocupação desenfreada e aumento da pobreza e degradação ambiental de territórios ocupados por povos e comunidades tradicionais (Ibid.).

Nesse processo, os espaços vazios nas áreas de morro do centro da cidade foram determinantes para o alargamento da ocupação nos mesmos. As possibilidades de trabalho próximo do local de moradia, o acesso aos serviços e equipamentos urbanos oferecidos, foram fatores de atraçãopara os moradores, que passaram a receber parentes e amigos, multiplicando os lotes ocupadose a construção de barracos que se espalhavam nos morros. Destaca-se ainda a importância da proximidade com os recursos naturais, uma vez que muitos desses novos moradores viviam em áreas rurais, e mantinham estreita relação com a terra (FREITAS et al., 20II). No entanto, não se pode considerar apenas o caráter econômico do povoamento da capital, esquecendo-se das trilhas traçadas pelas identidades locais e as territorialidades que referenciam os distintos modos de vida existes na capital (GUIMARÃES et al., 20II).

Esse "meio ambiente" que subiu o morro, respaldado por um conjunto de "leis ambientais" e de ordenamento territorial, e materializado na criação do PEFG ${ }^{\text {II }}$ em 1986 - que imprensa um

\footnotetext{
9 Inaugurado em 1926, o prédio foi projetado pelo arquiteto Joseph Pitilick e construído para substituir o antigo Mercado Municipal, possui formas ecléticas e neoclássicas e foi tombado em nível estadual. É acessível por duas das avenidas mais movimentadas do Centro de Vitória, a Princesa Isabel e a Jerônimo Monteiro, e atualmente oferece artesanatos diversos.

ro Jucutuquara é um bairro antigo de Vitória, localizado logo abaixo de Fradinhos, já a Praia do Canto é um bairro de classe média alta localizado na porção norte da Ilha.

II O Parque Estadual da Fonte Grande foi criado através da Lei Estadual no 3.875, de 31/o7/86. Possui uma área de 2.18 hectares e está dividido em duas porções distintas: a área A corresponde a cerca de 195 hectares, compreendendo o morro da Fonte Grande, Santa Clara, Bastos e Pedra dos Dois Olhos, enquanto a área B possui aproximadamente 23 hectares e compreende o morro do Mulundu e a Pedra do Vigia. Quase toda a extensão do PEFG está acima do nível altimétrico de $50 \mathrm{~m}$, sendo que o seu ponto culminante chega aos $308,8 \mathrm{~m}$, o mais alto do município (ES, 1986).
} 
territóriotradicionalmente ocupado por suas duas áreas - chegou interferindo e transtornando a vidacotidiana desse coletivo, com seus limites impostos, proibições e regras, desconsiderando que há muito tempo eles já estavam morando lá:

hoje eles ficam criando, falando que esse parque é deles, que as pessoas que moram ali não tem direito a nada, numa área em que eles estão chegando agora $\mathrm{e}$ criando isso aí. O que eles fazem com a gente é a mesma coisa de eu chegar na sua casa, no seu terreno, e falar "isso aqui é meu e você não tem mais direito, você sempre cuidou daqui mas agora quem vai tomar conta sou eu", porque pela idade do parque, é bem diferente da nossa existência aqui, você vê, eu nasci em 69, o parque é de 86 né? A minha juventude toda foi ali antes da criação do parque, e depois que foi criado tirou a minha liberdade naquela área ali (Inácio, 43 anos).

Assim, o parque é representado e vivenciado de formas distintas: enquanto para o coletivo o parque era morada (lugar de reprodução de vida e terra de trabalho) e passou a representar uma ruptura na vida social (na delimitação de espaço e na privação de práticas como caça, coleta e agricultura), como narrado por seu Juliano, morador do Campinho de 78 anos:

a gente trabalhava, roçava, fazia o diacho. Depois foi que veio este negócio de 'IBAMA' e trancou tudo que ninguém pode mais fazer nada. A mata era mata, a terra era terra (...). Tão querendo tirar a gente pra emendar tudo ao parque. (...) $\mathrm{O}$ parque não vem aqui pra falar com a gente, só os guardas falando pra gente não mexer no mato (...) quando eles vêm aqui, param pra tomar um café, pegar uma jaca, umas frutas e vão embora (Juliano, 78 anos) (FIGUEIRA, 2010).

Já para o poder público municipal e os ambientalistas preservacionistas, o parque é o espaço de reserva ambiental, de natureza que deve ser intocada, é o “pulmão de Vitória” e retirar os moradores do local torna-se a única alternativa, alegando uso indevido dos recursos e negando que os moradores do local gerenciaram uma apropriação do espaço “sustentável”. Dessa forma, estando o Campinho localizado em Área de Interesse Ambiental, Zona de Proteção Ambiental e Área de Proteção Ambiental do Maciço Central, o coletivo é proibido de melhorar suas casas, a PMV não investe em melhorias, próibe a ESCELSA de investir na iluminação e a CESAN em abastecimento de água e esgoto, criando, dessa forma, uma situação de precariedade para forçar a sair do lugar e, ao mesmo tempo, prevenir novas ocupações.

Diversos moradores demonstram que discordam da intenção da PMV de unir as duas 
áreas do parque e tirar as pessoas de lá, como afirma seu Inácio: "sou contra tirar as pessoas daqui, acho que tem que manter o povo aqui e reflorestar a área, seria bom pra gente e pro parque também, seria bom, quanto mais árvore plantada melhor, bom pra gente respirar, bom pra gente viver”. Joel, 34 anos, também nascido e criado no Campinho, acredita que a PMV deveria incentivar a permanência das pessoas, que contribuem para a preservação do território:

eu não acho uma boa ideia tirar as pessoas daqui para unir o parque, muito pelo contrário, eles deveriam é manter essas pessoas, deveriam apoiar essas pessoas, com água, tal, e manter um controle sobre essas pessoas, não deixar construir mais, manter tudo o que está. Mantendo as pessoas, que são antigas, assim como a minha família, os outros respeitam, não invadem, não tiram madeira. Agora se tirar, se vira uma coisa pública, as pessoas não respeitam mais, eles têm essa mentalidade. O parque tem que agradecer aos proprietários antigos daqui de cima como nós, o Gasparini, Zé Ganga, o pessoal do Schneider e outros que mantiveram isso aqui pouco povoado, senão estava tudo tomado, porque naquela época ninguém respeitava nada não, derrubavam a mata, construíam os barracos, invadiam mesmo. Era solto, agora tem mais controle, pode ver que as leis são de 90 pra cá. Se não fossem essas propriedades não teria parque, mas eles não respeitam, eles não têm um bom convívio com a comunidade.

Marta relata que o coletivo tem consciência do que a prefeitura deseja: “o interesse é tirar o pessoal lá de cima, eles tem interesse de tirar a gente daqui de cima, mas nós, a maioria, não tem interesse em sair daqui” e acredita na importância dos moradores mais antigosno morro para a preservação do mesmo: “(...) nós não chegamos aqui ontem, nós chegamos aqui tem muitos anos, entendeu? Eu acho que se não fosse nós aqui esta mata já tinha acabado e nãoexistiria mais nada aqui em cima" (Marta, 42 anos). Já o pai de Joel, seu Marcos, que mora na propriedade há mais de sessenta anos, também defende a importância da ocupação antiga das terras, relatando como ocorreu com sua família. Seu pai, Ícaro, era funcionário público estadual, conhecido como "guarda das matas de Vitória" por não permitir o desmatamento nem a ocupação desordenada do morro:

antes (a propriedade) era até lá em baixo, lá na rua (Rua Sete de Setembro, no Centro de Vitória-ES), mas devido à população aumentando, o pessoal foi invadindo, invadindo, aí eu impedi o pessoal entrar. Na época do meu pai também impediu o pessoal entrar, senão tinha barraco até lá em cima nas torres, aí nós não deixamos mais invadir.

Corroborando com essa ideia de que as propriedades e suas atividades foram as responsáveis pela contenção da ocupação na região, o plano de manejo do PEFG reforça que a pecuária contribuiu "para evitar a ocupação dessas áreas, que na sua maioria, estão acima da cota 
de 50 m" (SEAG-IDAF et al., 1996, p. 22), o mesmo raciocínio do vice presidente da AAPFG, que ao relatar a história de ocupação do parque da Fonte Grande, destacou a cafeicultura como atividadede agricultura familiar imprescindível para a preservação da mata do parque:

antigamente se cultivava café debaixo das sombras das árvores, porque o café não era igual ao café que a gente conhece hoje, o café conilon, que tem que ser produzido debaixo do sol, era o café arábica, que só podia sobreviver se fosse plantado debaixo das árvores, então eles limpavam a área embaixo das árvores e plantavam o café, razão porque preservou-se toda a floresta, porque se tivesse derrubado a floresta não teriam plantado o café, então a existência de grande parte da floresta aqui se deve ao café.

Nesse cenário de conflito de interesses e perspectivas entre esses atores, a ameaça constante de remoção e remanejamento - sustentada no discurso da PMV pela demanda de conservação dos recursos naturais - gera, no coletivo, insegurança e instabilidade. Mas esse encontra alternativas para várias situações adversas, como a falta d'água, luz elétrica, banheiro, segurança, etc., não abrindo mão de uma intensa relação com o território, laços de parentesco e de afinidade com os demais membros, o coletivo resiste e sabota às inúmeras investidas da PMV, ao mesmo tempo em que vem tomando atitudes mais ostensivas, procurando dar visibilidade pública aos problemasdo coletivo, reivindicando o reconhecimento de seus direitos, pressionando e exigindo do poder público municipal uma resposta à sua situação "provisória", já que seus integrantes ou vivem mudando de casa - através do Aluguel Provisório - ou vivendo num território cada vez mais abandonado, sem qualquer investimento público, ainda não totalmente "verde", e muito menos, com cidadania.

Uma forma de resistência adotada pelo coletivo frente ao processo em domesticação e disciplinamento do território por parte da PMV é dando continuidade a usos agropecuários num município em que o Plano Diretor $\mathrm{Urbano}^{\mathrm{I} 2}$ do município não reconhece mais outros usos que não os urbanos, embora aqueles permaneçam mais vivos que nunca nesse território.

\footnotetext{
${ }^{12} \mathrm{O}$ modelo de ordenamento territorial do município foi normatizado através do Plano Diretor Urbano de Vitória PDU. O primeiro PDU foi instituído em 1984 e a partir de 2001 - com a aprovação do Estatuto da Cidade (Lei Federal no 10.257), onde foram estabelecidos novos instrumentos de planejamento e controle do crescimento das cidades - o PDU municipal foi revisado e seu novo texto aprovadoem 2006, com a implementação da Lei Municipal no 6.705/o6, elaborada já no âmbito da Agenda 2i Local. Objetivando o ordenamento e a imposição de restrições à ocupação de seu território, o novo PDU é um instrumento destinado a regular o uso e a ocupação do solo para cada uma das zonas em que se subdivide o território do município, tendo como objetivos: I - fazer cumprir as funções sociais da cidade e da propriedade urbana, tendo em vista o estado da urbanização, as condições de implantação da infraestrutura de saneamento básico, do sistema viário e do meio físico; II - atribuir diretrizes específicas de uso do solo para as zonas (PMV, 2006).
} 
Dos diversos atores do Campinho que vivenciam práticas agrárias no morro, seu Eduardo, 68 anos, ao ser indagado se se considerava mesmo um lavrador, respondeu que "quem tem comércio é comerciante, quem dirige carro é motorista, se eu trabalho na roça eu sou lavrador(...) a minha renda é isto aqui, é a jaca, a mandioca, o mamão, o fruta pão, a goiaba, o franguinho, vendo no morro, de casa em casa, na feira, eu me viro (...) só tenho essa renda, uma média de um salário mínimo”.

Seu Eduardo, mineiro de Aimorés, em sua propriedade de cerca de doze mil $\mathrm{m}^{2}$ planta mandioca, batata doce, cana, feijão guando, coentro, salsinha, cebolinha, abóbora, chuchu, além de manga, jaca, jabuticaba, acerola, pitanga, fruta pão, abacate, e de sua criac,ão de cem cabeças de galinha, que vende no morro e na feira do bairro de Santo Antônio, na quarta-feira, aos sábados em São Pedro I e aos domingos em São Pedro II. Mas remédios do mato, muda e semente disse que não vende, dá para as pessoas, "se perguntar em qualquer casa do morro se conhece o véio da chácara, o véio da banana, o véio do aipim eles vão falar que conhecem”. Disse que gosta tanto do lugar que não quer mais sair de lá: "eu nunca tive uma residência na Terra tão agradável como essa que eu tenho aqui, mas em todos os pontos de vista, apesar dos pesares, a alegria aqui é muito maior que a tristeza (...). Eu pretendo ser enterrado aqui, não em nenhum cemitério não, aqui mesmo, enterrado aqui, eu gostaria de ser enterrado aqui”.

Outros moradores relatam sua origem e sua vida no Campinho. Seu Juliano, 78 anos, veio de Itamaraju, sul da Bahia, em meados da década de 8o: "eu vim de lá porque meus tios vieram tudo embora e eu fiquei sozinho, a mulher tinha me largado há um bocado de tempo. Aí eu vim pra cá”. Desde então seu Juliano trabalha como agricultor em sua propriedade, consumindo o que produz: “(...) eu planto é aipim, banana, jiló, mamão, cana, mandioca, banana, côco, cebolinha, salsinha (...) eu não compro verdura não”. Uma característica marcante de seu Juliano é o prazer que demonstra em distribuir legumes, verduras, hortaliças e frutas cultivadas por ele aos vizinhos, como numa oportunidade em que me disse que plantava cana só para ter a satisfação de doar, já que não conseguia chupá-la por não ter mais os dentes.

Essa prática é comum entre o coletivo, não só entre os lavradores, mas com todos, já que sempre tem em seus quintais frutas, ervas medicinais, temperos, ovo de galinha, ou a mesma, que doam entre si e futuramente são correspondidos, elementos que sugerem o exercício da dádiva no coletivo (MAUSS, 2003 apud FREITAS et al., 20II). Seu Juliano possui uma pequena quantidade de galinhas e uma parceria na criação de porcos com sua vizinha, a Daniela, com quem os compra, 
os engorda e depois vende a carne:

(...) eu comprei porco pra ela, e ela ficou criando, eu tentei vender, mas é difícil. Outro dia nós matamos um á, deu uns seis quilos de carne. Vendemos tudo (...). Eu e ela vendemos dezesseis cabeças de porco e galinha eu criei também (...).Mas agora eu vou criar de novo.

Marcílio, 6o anos disse que veio de Itaoca, um distrito do município de Cachoeiro de Itapemirim em 1965, para trabalhar na propriedade de Machadinho: "trabalhei oito anos pra ele, depois trabalhei pra firma dele, aí depois entrei na prefeitura”.

Seu Marcílio mora numa casa de alvenaria com um quarto, ao lado da casa de seu filho Lucas, no mesmo quintal, cercado por bambus e com galinhas e patos espalhados ao lado de árvores frutíferas, seu jardim e sua horta. Em conversa realizada em sua residência, disse que pegava o bambu na área do parque "eu vou no meio dos bambus", ciente de que estava ajudando a cuidar do mesmo, já que os bambus estavam tomando conta da área. Mostrava ainda a legitimidade de sua permanência no local, baseada na sua relação com a terra e na (re)significação das categorias de parque, proteção e preservação da natureza, plantando árvores e flores que ajudavam a aumentar a floresta, indo ao encontro à ideia de preservação do parque (GUIMARÃES et al., 20II).

Ao ser perguntado desde quando plantava ali, seu Marcílio respondeu: "desde que eu vim pra cá, eu vim pra cá pra cuidar de roça”. E disse que vendia parte do que plantava: “já plantei horta aqui e vendia. Hoje não está dando nada não (...). Eles vinham comprar aqui”. Marcílio também tem um pequeno bar ao lado do campo de futebol, que foi construído há muito tempo: “mais de vinte anos. Desde que eu vim pra cá eu vendo alguma coisinha, não tinha luz, eu vendia querosene. Era melhor que hoje”. E explica por que antigamente era melhor: "hoje tem mais ação, não tinha luz, nem televisão, quase todo mundo ia dormir, né? Hoje não, tá tudo claro, né?, fica até mais tarde (...). Tira mais o sossego da gente, né? Eu fazia uma fogueirinha e ficava ao redor”.

Nessa paisagem híbrida, na qual o rural e o urbano se misturam, tem destaque o gado de Joel, 34 anos, gado esse considerado aqui mais um ator não-humano com agência (LATOUR, 200o), já que interfere na dinâmica do morro, quando, ao entrar em áreas fora da propriedade da família Lírio, gera conflitos com a administração do PEFG, com os moradores e atrapalha as partidas de futebol.

Assim como seu bisavô, seu avô e seu pai, Joel, a quarta geração da família Lírio nessas terras, 
cuida do gado e se orgulha de desenvolver uma atividade considerada rural no espaço urbano do Centro de Vitória: “eu faço por amor mesmo, entende? Para dar continuidade à história da família, isso é a história da família, existe em nossa propriedade desde 1888 com meu bisavô Fernado, que trouxe cinquenta cabec,as de Viana”.

Joel conta que até a época de seu avô, Ícaro, cuidavam do gado e plantavam café em dois dos sete alqueires da propriedade, mas que depois deram fim no café e continuaram apenas com o gado. Joel atualmente está com trinta cabeças do gado leiteiro da raça Girolando - entre vacas, bois, bezerros, novilhas e garrotes - resultado do cruzamento entre as raças Gir e a Holandesa. Disse que essa mistura é muito boa, já que "o Gir é muito resistente e a Holandesa é leiteira, produz muito, assim a Girolando é uma raça que se adapta bem ao morro e ao mesmo tempo é muito boa produtora de leite". Não é de se espantar essa atividade rural na capital do estado em pleno século XXI, já que, segundo dados do Censo do IBGE, em 2010 o município de Vitória possuía um total de 144 cabeças de rebanho bovino (IBGE, 2013b), sendo 32 cabeças de vacas ordenhadas (Id., 2013c), que produziam 22 mil litros de leite por ano (Id., 2013d).

Relatou que adquiriu esse conhecimento "no morro mesmo, com as pessoas antigas daqui, da família e vizinhos", porque, segundo ele, o que falam que hoje é o parque da Fonte Grande, antes era tudo propriedade rural "quando eu tinha meus dez, doze anos eu saía de casa às cinco da manhã, minha mãe ficava doida, eu subia, ia lá no Zé Ganga, no Gabriel, no Batelão, na família Gasparini, juntava o gado deles e ia tirar leite, sem cobrar um real, só por prazer. Era o dia todo em cima de cavalo no pelo, atrás das vacas e cuidando delas”.

Trabalhando atualmente como técnico de manutenção industrial numa multinacional no Porto de Vitória, Joel contratou um funcionário para auxiliá-lo, que é pago exatamente com a venda de leite para uma sorveteria em Itararé, um bairro de Vitória, atualmente seu único comprador, "eu já cheguei a vender o leite na comunidade e vendia até queijo". Consegue cerca de trinta litros de leite por dia, de segunda a segunda, sendo dois galões por dia, "hoje tiramos o leite às sete da manhã, tranquilo, mas quando entrava às seis e meia eu acordava às quatro horas, entregava lá em baixo o leite, e depois ia para o serviço”.

Já as narrativas de dona Évora, 65 anos, outra nativa do Campinho, demonstram uma intensa relação com a terra, ao longo de suas seis décadas de vida: "eu nasci, cresci, casei, tive filhos, lá em cima, era do meu pai, lá em cima (...). Ali tudo era do meu pai, meu pai tinha uma roça de milho e de feijão, aí tinha tudo! Era uma chácara ali. (...) meu pai vendia manga, 
vendia milho, parece mentira (...)". Informa ainda que sempre plantou: "eu tenho taioba, pimenta, manjericão, hortelã, cidreira, pimenta, tem saião, tem boldo (...) Eu fui criada com o meu pai, eu aprendi com ele".

Dona Évora lembrou da época em que outros moradores, hoje todos falecidos, compunham o coletivo, como seu pai Silvino, "um cabloco, filho de índio pego a laço", e sua mãe, dona Eva, "lavadeira, lavava roupa lá em cima, no Campinho", além de dona Luíza, dona Ozide, dona Leocádia, Zé Ganda, Maria Luíza, dona Natalina, seu Pedro, dona Zizinha, seu Luiz, dona Mercedes, dona Maria Rosa, Tonico, dona Iolanda, dona Sebastiana, seu Benjamin, dona Iaiá, dona Zefina, dentre outros, nos alertando para entender que o Campinho não é apenas o que vemos hoje, com os moradores atuais, mas que muito antes outras pessoas já estavam lá, subindo e descendo o morro sem as escadarias, vivendo nas casas de palha, de estuque, carregando lata d'água na cabeça (como ainda acontece), iluminadas por lamparinas (e não com os gatos de hoje).

Narrou ainda que estudava no Grupo Escolar Lizerina Lírio, que funcionou na Fonte Grande entre as décadas de 40 e 60 , que passeava de bonde pela cidade com seu pai, que comprava, ainda muito pequena, carne seca e pão nas duas vendas que tinham no morro, lembrou do fogão à lenha que seu pai construiu com uma chaminé em cima, para não cheirar a fumaça, "aí tinha café a toda hora, era panela de barro para cozinhar o feijão, carne seca no feijão, era uma outra história”, narrativa que nos desloca para o espaço biofísico do território, como ele é significado e lembrado a partir de relações que se constituíram com os diversos elementos humanos e não-humanos do coletivo e com a própria cidade (GUIMARÃES et al., 20II).

Mas em outubro de 2010 dona Évora e seu companheiro mudaram-se para a parte baixa do morro da Fonte Grande, já que passaram a receber o Aluguel Provisório, e a casa foi demolida pela PMV, mudando a paisagem do lugar. Mas mesmo saindo do Campinho dona Évora afirma que continuava plantando jiló, abóbora, coentro, taioba, chuchu, boldo, manjericão, limão, batata doce, pimenta, dentre outros, no quintal atrás da casa onde mora de aluguel, na parte baixa do morro da Fonte Grande. Relatou ainda que havia pagado a um vizinho para que trouxesse terra do quintal de sua casa demolida na Escadaria do Céu para poder plantar como lá em cima, com a mesma terra, como se o Campinho descesse junto. 


\section{CONSIDERAÇÕES FINAIS}

Os interesses pelo lugar são diversos, diversas também são as versões sobre o uso de espaço e sua cosmografia, já que, enquanto o coletivo reforça seu pertencimento e a possibilidade de permanecer no território, os agentes governamentais, representados pelos técnicos da SEMMAM, reafirmam o remanejamento do coletivo como única forma de preservar o "meio ambiente".

No entanto, o coletivo tem possibilidades para a solução do conflito, inscritas nos marcos legais, tais como o Decreto Federal no 6.040/o7, que institui a Política Nacional de Desenvolvimento Sustentável dos Povos e Comunidades Tradicionais, bem como a Lei no 9.985/oo, que institui o Sistema Nacional de Unidades de Conservação, ou seja, seus direitos praticados e garantidos por lei, ainda não lhe foram reconhecidos.

O SNUC apresenta-se como um ator híbrido nesse conflito socioambiental, já que possibilita alternativas que garantem a permanência de humanos no território, podendo representar um caminho para a solução da situação do coletivo do Campinho, introduzindo um elemento fundamental no processo de classificação da categoria de uma unidade de conservação: a “população tradicional”, outro híbrido, um misto de natureza e cultura (LATOUR, I994). Esse "elemento" passa por um procedimento de purificação e tradução por parte de várias instâncias do Estado - como a Comissão Nacional de Desenvolvimento Sustentável dos Povos e Comunidades Tradicionais - CNPCT, as Secretarias de Meio Ambiente e as Universidades - em seu processo de autoidentificação, necessário para a aplicação da lei, já que, para dar início à discussão acerca dos direitos dos grupos, eles devem ser primeiro oficializados pelo Estado e seus agentes (LOBÃO, 2006).

Já o Decreto Federal no 6.040/o7, que institui a Política Nacional de Desenvolvimento Sustentável dos Povos e Comunidades Tradicionais, apresenta-se como a legislação que possibilita tanto assegurar a permanência no território, quanto fundamentar a mudança da categoria de unidade deProteção Integral para a de Unidade de Uso Sustentável. Conforme inciso I do Art. $3^{\circ}$, são considerados Povos e Comunidades Tradicionais:

grupos culturalmente diferenciados e que se reconhecem como tais, que possuem formas próprias de organização social, que ocupam e usam territórios e recursos naturais como condição para sua reprodução cultural, social, religiosa, ancestral e econômica, utilizando conhecimentos, inovações e práticas gerados e 
transmitidospela tradição (BRASIL, 2007).

Em seu anexo, além de objetivos específicos, o Decreto institui seu objetivo geral:

a PNPCT tem como principal objetivo promover o desenvolvimento sustentável dos Povos e Comunidades Tradicionais, com ênfase no reconhecimento, fortalecimento e garantia dos seus direitos territoriais, sociais, ambientais, econômicos e culturais, com respeito e valorização à sua identidade, suas formas de organização e suas instituições (BRASIL, 2007, Art. $2^{\circ}$ ).

Dessa forma, diante da intenção da SEMMAM em unir as duas porções do PEFG, o momento é oportuno para iniciar um debate entre a sociedade civil e o poder público sobre a necessidade de adequação da UC ao SNUC. Mudando a categoria da UC - passando do grupo das de Proteção Integral, para uma de Uso Sustentável, como, por exemplo, uma Reserva de Desenvolvimento Sustentável - o coletivo, enquanto "comunidade tradicional", seria incorporado à área.

Essa incorporação exigiria do coletivo um investimento em sua organização política e a apropriação dessas categorias ambientais que parecem, no entanto, estarem presentes na perspectiva dos moradores, já que os mesmos demonstram consciência da necessidade de negociar com o poder público para continuar vivendo no território:

vai ter que ter tipo uma troca, né? A prefeitura cede, deixa a gente morar lá, com saneamento básico, com uma condição de vida melhor pra gente, e a gente vai ajudar a preservar, entendeu? Organizar tudo, com tambores de lixo pra não ter mais lixo espalhado (Inácio, 43 anos).

eu sei que é uma área de reserva, né? Mas a gente não tá aqui pra atrapalhar, a gente está aqui pra isso: fazer o que a reserva precisa. (...) plantar, cuidar da natureza, né? (Marcílio, 6o anos).

(...) Eu imagino ali como se fosse um conjunto habitacional, com aquelas casinhas que estão ali, no mesmo lugar delas, de alvenaria, entendeu? Tudo pintadinha, com aquele laranja forte, aquele verde forte, mas separadinho assim, tudo calçadinho, um lugar pra você pisar e não sujar o pé de lama, um banheirinho bom, mesmo que não tenha o esgoto mas com uma fossa descente, fechadinha, com cerca no campo, criar programa ambiental, cursos na área ambiental para as crianças, para os jovens, para cuidar do parque, ajudar a preservar, conscientizar eles. Se isso acontecesse, eu sei que isso é difícil, seria uma área bonita, alegre,e todo mundo feliz, todo mundo tranquilo. Acredito na convivência entre o parque e a gente, tranquilo, desde que tenha qualidade de vida ali pro povo (Inácio, 43anos). 
Cabe à PMV reconhecer que os próprios moradores têm contribuído e continuarão contribuindo na preservação do parque, criando um ambiente com a cidadania que todos os habitantes da cidade deveriam ter direito de exercer, com moradia de qualidade, água, luz, esgoto, segurança pública, coleta de lixo, acessibilidade, saúde, educação, cultura, diversão, etc., ressignificando o Campinho, de um território abandonado e "provisório" para um território vivo e de direito, onde o coletivo agenciaria o presente, à luz da memória de sua trajetória, se reapropriando de seus projetos para o futuro.

\section{REFERÊNCIAS}

ACSELRAD, H. As práticas espaciais e o campo dos conflitos ambientais. In: (org.).

Conflitos ambientais no Brasil. Rio de Janeiro: Relume Dumará; Fundação Heinrich Böll, 2004.

BANCK, G. Dilemas e símbolos: estudos sobre a cultura política do Espírito Santo. Vitória: Instituto Histórico e Geográfico do Espírito Santo, 1998. (Cadernos de História, n. 13).

BATESON, G. Naven: um exame dos problemas sugeridos por um retrato compósito da cultura deuma tribo da Nova Guiné, desenhado a partir de três perspectivas. São Paulo: EDUSP, 2008.

BRASIL. Decreto no 6.040, de 07 de fevereiro de 2007. Institui a Política Nacional de Desenvolvimento Sustentável dos Povos e Comunidades Tradicionais. Brasília, 2007.

Lei $\mathrm{n}^{\circ}$ 9.985, de 18 de julho de 2000. Institui o SNUC - Sistema Nacional de Unidades de Conservação. Brasília, 2000.

CICCARONE, C. A igualdade "por baixo" e a escadaria "do céu: erradicação da pobreza, ambientalismo e pluralidade num caso de conflito socioambiental na cidade de Vitória”. In: SINAIS

- Revista Eletrônica. Ciências Sociais. Vitória: CCHN, UFES, Edição noo o8, v.ı, Dezembro. 2 oı. et al. Os Tupiniquim e a cidade. Vitória-ES: Relatório de Pesquisa FACITEC, Prefeitura Municipal de Vitória, 2008.

DERENZI, S. Biografia de uma Ilha. Rio de Janeiro: Ed Pongeti, 1965.

DESCOLA, P. Ecologia e Cosmologia. In: DIEGUES, Antonio Carlos (org.). Etnoconservação: novos rumos para a conservação da natureza. São Paulo: Hucitec, NUPAUB - USP, 2000.

ELTON, E. Logradouros antigos de Vitória. Vitória: Instituto Jones dos Santos Neves, 1986.

FIGUEIRA, F. Participação política das comunidades tradicionais na Fonte Grande. In: Jornada 
de Iniciação Científica (Programa Institucional de Iniciação Científica - PIBIC/PIVIC). UFES: Vitória, 2010.

FREITAS, M. A. F. de; CICCARONE, C. Entre as áreas do parque há um Campinho: reflexões sobre um conflito socioambiental em Vitória-ES. In: XXVIII Reunião Brasileira de Antropologia.São Paulo: 2012.

; SOUZA, E. Contos e encontros: ocupação de áreas de interesse ambiental e conflitos entre políticas públicas e comunidades locais em Vitória-ES. In: I Seminário Nacional da PósGraduação em Ciências Sociais. Vitória: UFES, 2oIr.

GEERTZ, C. O saber local: novos ensaios em antropologia interpretativa. Petrópolis: Vozes, 2006.

GOVERNO DO ESTADO DO ESPÍRITO SANTO - ES. Lei no 3.875: Cria o Parque Estadual da Fonte Grande. Vitória, ES, 1986.

GUIMARÃES, F.; SILVA, A. Ecologia política e territorialidades: da epistemologia ambiental ao desenvolvimento multicultural. In: XXVIII Congresso Internacional da ALAS. Recife, 20II.

INGOLD, T. Humanidade e Animalidade. Revista Brasileira de Ciências Sociais, ANPOCS, n. 28, ano Io, p. 39-53, junho de 1995 .

Instituto Brasileiro de Geografia e Estatística - IBGE. Vitória-ES: População 20ıo. Disponível 735 em: http://www.ibge.gov.br/cidadesat/topwindow.htm? I. Acesso em os de janeiro de 2013a.

Espírito Santo-ES: Bovinos - efetivo dos rebanhos. Disponível em: http://www.ibge.gov.br/cidadesat/comparamun/compara.php? codmun=320530\&coduf=32\&tema $=$ prodpec2oII\&codv=voi\&lang $=$. Acesso em os de janeiro de $2013 \mathrm{~b}$.

Espírito Santo-ES: Vacas ordenhadas - quantidade. Disponível em: http://www.ibge.gov.br/cidadesat/comparamun/compara.php? codmun=320530\&coduf=32\&tema $=$ prodpec2ori\&codv =vi3\&lang $=$. Acesso em os de janeiro de $2013 \mathrm{c}$.

Espírito Santo-ES: Leite de vaca - produção - quantidade. Disponível em: http://www.ibge.gov.br/cidadesat/comparamun/compara.php? codmun=320530\&coduf=32\&tema $=$ prodpec2ori\&codv=vis\&lang=. Acesso em os de janeiro de $2013 \mathrm{~d}$.

LATOUR, B. A Esperança de Pandora. Bauru: EDUSC, 200.

Ciência em ação: como seguir cientistas e engenheiros sociedade afora. São Paulo: Editora UNESP, 2000 .

Jamais fomos modernos: ensaio de antropologia simétrica. Rio de Janeiro: Editora 34, 1994 . 
LITTLE, P. E. Territórios sociais e povos tradicionais no Brasil: por uma antropologia da territorialidade. Série Antropológica, no 322, Brasília. UnB, 2002. http://vsites.unb.br/ics/dan/Serie322empdf.pdf.

LOBÃO, R. Cosmologias políticas do neocolonialismo: como uma política pública pode se transformar em uma política do ressentimento. Tese (Doutorado em Antropologia Social) Institutode Ciências Sociais, Universidade de Brasília. Brasília, 2006.

MAUSS, M. Ensaio sobre a dádiva: Forma e razão da troca nas sociedades arcaicas. In: Sociologia e Antropologia. São Paulo: Cosac Naify, 2003.

PREFEITURA Municipal de Vitória - PMV. Vitória em dados: População residente em Vitória (ES) por gênero e bairros - 2010. Disponível em http://legado.vitoria.es.gov.br/regionais/Censo_2010/Tabı_sinopse_pop.asp. Acesso em 05 de janeiro de 2013.

Lei no 6.967/o7: Institui Programa Habitacional de interesse social no âmbito do Projeto Terra. Vitória, 2007.

. Lei no 6.705: Institui o Plano Diretor Urbano do Município de Vitória. Vitória, 2006.

Plano de Manejo da APA do Maciço Central. Vitória, ES, 1992.

ROCHA, L. Viagem de Pedro II ao Espírito Santo. Vitória: Arquivo Público do Espírito Santo, 2008. (Coleção Canaã, volume 7).

SILVA, S. et al. São Benedito: Território negro urbano. In: Quilombos urbanos em Vitória: etnicidade e territorialização. Vitória: Relatório de Pesquisa FACITEC, Prefeitura Municipal de Vitória, 2007.

SEAG-IDAF; SEMMAM; CEPEMAR. Plano de Manejo: Parque Estadual da Fonte Grande. Vitória-ES, 1996.

SOUZA, E.; GUIMARÃES, F. Outras biografias da ilha: sobre narrativas de ocupação de áreas de interesse ambiental e conflitos entre políticas públicas e comunidades locais. In: VIII Encontro de História da ANPUH. Vitória, 2010.

VIVEIROS DE CASTRO, E. A inconstância da alma selvagem e outros ensaios de antropologia. São Paulo: Cosac \& Naify, 2002. 